\title{
Development and tests of Molybdenum armed copper components for MITICA ion source ${ }^{\text {a) }}$
}

\author{
Mauro Pavei ${ }^{1, b)}$,Bernd Böswirth ${ }^{2}$, Henri Greuner ${ }^{2}$, Diego Marcuzzi ${ }^{1}$, Andrea \\ Rizzolo ${ }^{1}$, Matteo Valente ${ }^{1}$ \\ ${ }^{1}$ Consorzio RFX, Corso Stati Uniti, 4, I-35127, Padova, ITALY \\ ${ }^{2}$ Max-Planck-Institut für Plasmaphysik, Boltzmannstrasse 2, D-85748 Garching, Germany
}

(Presented 27 August 2015; published online 3 November 2015)

\section{ABSTRACT}

In order to prevent detrimental material erosion of components impinged by back-streaming positive $\mathrm{D}$ or $\mathrm{H}$ ions in the Megavolt ITER Injector \& Concept Advancement (MITICA) beam source ${ }^{1}$, a solution based on explosion bonding technique has been identified for producing a $1 \mathrm{~mm}$ thick molybdenum armour layer on copper substrate, compatible with ITER requirements ${ }^{2}$. Prototypes have been recently manufactured and tested in the high heat flux test facility GLADIS ${ }^{3}$ to check the capability of the molybdenum-copper interface to withstand several thermal shock cycles at high power density. This paper presents both, the numerical fluiddynamic analyses of the prototypes simulating the test conditions in GLADIS as well as the experimental results.

\section{INTRODUCTION}

The operation of the thermonuclear fusion experiment ITER requires additional plasma heating via injection of high energy neutral beams; two injectors will deliver a total heating power of $33 \mathrm{MW}$. The MITICA experiment is the prototype and the test bed of the ITER Heating and Current Drive Neutral Beam Injectors ${ }^{4}$ (HNB); it is in the final design phase and will be procured and installed in PRIMA facility ${ }^{5}$ (Padova Research on Injector Megavolt Accelerated) in Padova, Italy. The beam of MITICA injector is generated by $1 \mathrm{MV}$ acceleration of $40 \mathrm{~A}$ of $\mathrm{H}-$ or D- ions, extracted from a Radio Frequency (RF) ion source. The presence of back-streaming positive ions (BSI+) with energy mainly concentrated around $10 \mathrm{keV}$ and in the range $100 \div 400 \mathrm{keV}$, generated by secondary particle reactions within the accelerator electrostatic grids and scattered back towards the RF source, causes serious problems to the impinged components. In fact, the high power density deposition and the material erosion by sputtering can seriously damage the parts. Such an eroded material pollutes the plasma and it is then detrimental for the ion source operation.

${ }^{a}$ Contributed paper published as part of the Proceedings of the 16th International Conference on Ion Source, New York, USA, August, 2015.

b) Corresponding Author: Mauro Pavei. Electronic mail: mauro.pavei@igi.cnr.it.

\section{BACKGROUND OF THE ACTIVITIES}

Explosion bonding was identified, together with plasma spraying, to be investigated as suitable technology for producing plasma facing components with $1.0 \mathrm{~mm}$ thick molybdenum armour layer on copper sub-structures, having molybdenum much lower sputtering yield with respect to copper. Whilst plasma spray was almost immediately discarded, due to the porosity of the molybdenum coating layer and the weak adhesion strength of the coating to the copper substrate, the explosion bonding gave good preliminary results and was further investigated. In parallel to improvements for the manufacturing of the components, developed through the production of several prototypes, thermal shock and thermal fatigue tests were successfully performed on small samples (front surface $20 \mathrm{~mm} * 22 \mathrm{~mm}$ ), as well ${ }^{6}$. Before adopting the molybdenum armed copper components for MITICA ion source, a further test for investigating the actual effects on the molybdenum surface, when it is exposed to a positive hydrogen ion beam, with energy and flux equivalent to the BSI+ ones, was considered necessary. The Garching Large Divertor Sample Test Facility (GLADIS) ${ }^{3}$ at Max-Planck-Institut für Plasmaphysik (IPP) has been identified as the most suitable for performing this investigation at $41 \mathrm{kV}$ acceleration voltage and $20 \mathrm{MW} / \mathrm{m}^{2}$ heat flux.

\section{PROTOTYPE DESIGN, ANALYSES AND MANUFACTURING}

Dedicated Mo-coated copper prototypes to be tested in GLADIS facility have been designed and manufactured. Each prototype was obtained from explosion bonded samples (8 $\mathrm{mm}$ thick copper plate with $1 \mathrm{~mm}$ thick molybdenum sheet over it). The overall dimensions of each prototype were: $175 \mathrm{~mm}$ x $44 \mathrm{~mm}$ x $10 \mathrm{~mm}$. In order to perform the active cooling during the tests, four $4 \mathrm{~mm} \mathrm{x}$ $5 \mathrm{~mm}$ cooling channels in each prototype have been first machined and then closed by means of an electroformed copper layer. Both prototypes ends were machined in order to be connected with stainless steel (SS) water manifolds; 
the leak tightness being guaranteed by an additional electroformed copper layer over the joints. Different configurations have been then investigated, concerning the prototypes assembly, in order to test 2 prototypes at the same time.

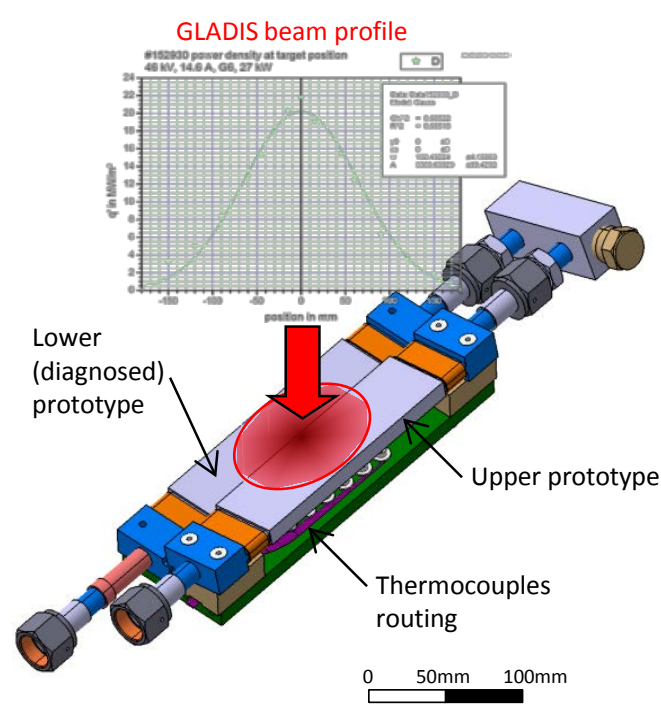

Figure 1: 3D view of one of the Mo-Cu prototypes

The arrangement shown in Figure 1, with one prototype partially masking the other one was chosen. It was then possible to install six thermocouples inside drilled holes on the side of the lower prototype, to make direct temperature measurements on the piece near to the cooling channels (T1-T6 in Figure 2).

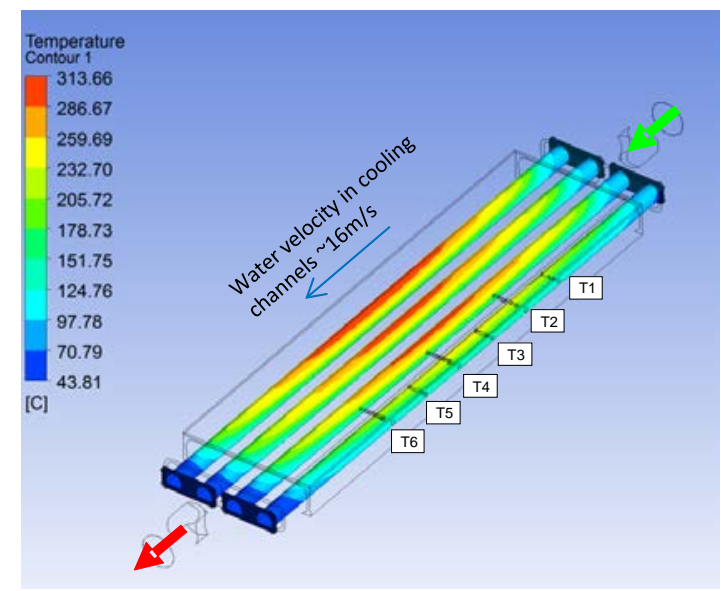

Figure 2: prototype cooling channels surface temperature contour plot. Positions and labeling of the thermocouples are also shown.

Coupled Computational Fluid Dynamic (CFD) and Finite Element (FE) thermal analyses were performed, verifying the capability of the prototypes to withstand the GLADIS beam at full power, in steady state. The applied heat load was derived from the experimentally measured power density profile of the GLADIS beam, corresponding to a Gaussian distribution with a peak power density of 20 $\mathrm{MW} / \mathrm{m}^{2}$. The cooling water mass flow rate was set to 1 $\mathrm{kg} / \mathrm{s}$, corresponding to water velocity in the cooling channels of about $15 \mathrm{~m} / \mathrm{s}$. A contour plot of the temperatures on the cooling channel walls, resulting from the CFD analyses, with indication of the thermocouple positions and layout, is shown in Figure 2. The temperatures calculated at the thermocouples tips are reported in Table 1 (together with the related temperatures recorded during the tests, as explained in the following paragraph). The maximum temperature resulting from CFD-FE analyses on the molybdenum surface was about $630^{\circ} \mathrm{C}$

\section{TESTS AND RESULTS}

The complete sample was installed on the GLADIS manipulator arm. Two actively cooled scrapers were installed to protect the water connections of the prototypes from the GLADIS beam. The recording of the water inlet and outlet temperatures, allows the calorimetric estimation of the heat transferred to the prototypes. An infrared (IR) camera looking at the front of prototypes was installed for video recording of the molybdenum surface during the pulses. A front picture of the prototypes installed in GLADIS is shown in Figure 3.

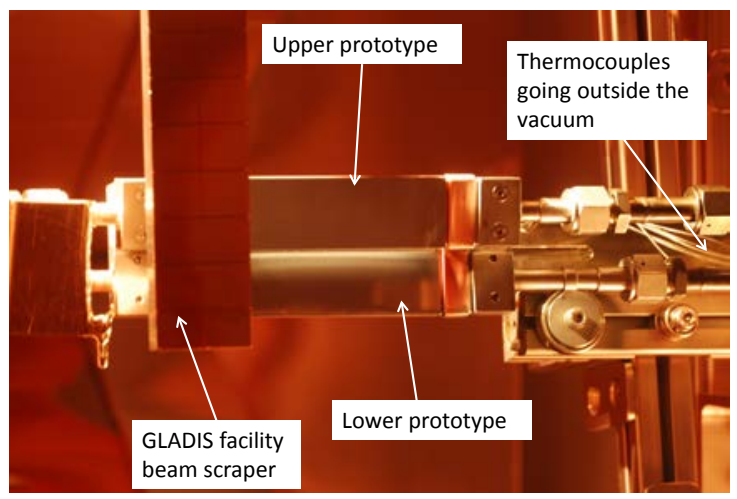

Figure 3: view of prototypes, as installed in GLADIS facility (picture taken from the video-camera) .

A two-colour-pyrometer QKTR-D (Tsurf_Mo_2) and a one-colour-pyrometer KTR (Tsurf_Mo_1) were used to get 2 additional measurements of the molybdenum surface temperature, adjusted to the centre of the lower prototype. The lower prototype was mechanically polished, therefore we used an emissivity $\varepsilon=0.2$ for the one-colour pyrometer and $\varepsilon=0.07$ for the IR camera (wavelength 8-11 $\mu \mathrm{m}$ ). After a first commissioning phase at reduced power, 100 pulses at the nominal power, lasting 10 s each were applied. The heating up and the cooling down of the mock-ups were recorded with an IR- camera (Figure 4). Figure 5 summarizes the maximum temperatures of the thermocouples $(\mathrm{T} 1, \ldots, \mathrm{T} 6)$ and the surface temperature, measured by the pyrometers (Tsurf_Mo_1, Tsurf_Mo_2), for each pulse. In Table 1 the average values of the same 
temperatures are instead reported and compared with the ones obtained from the CFD -FE analyses.

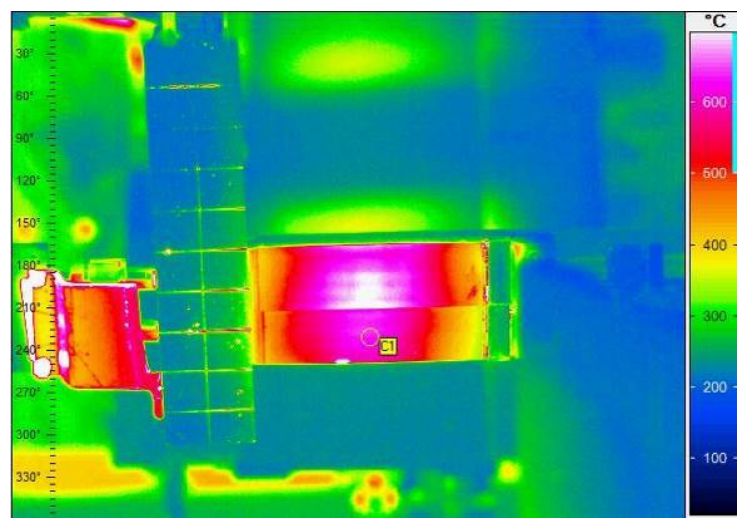

Figure 4: IR camera picture taken at the end of the last $20 \mathrm{MW} / \mathrm{m}^{2}$ heat pulse. The surface temperature of the upper mock-up seems higher since only the lower mock-up is polished and the resulting emissivity is lower.

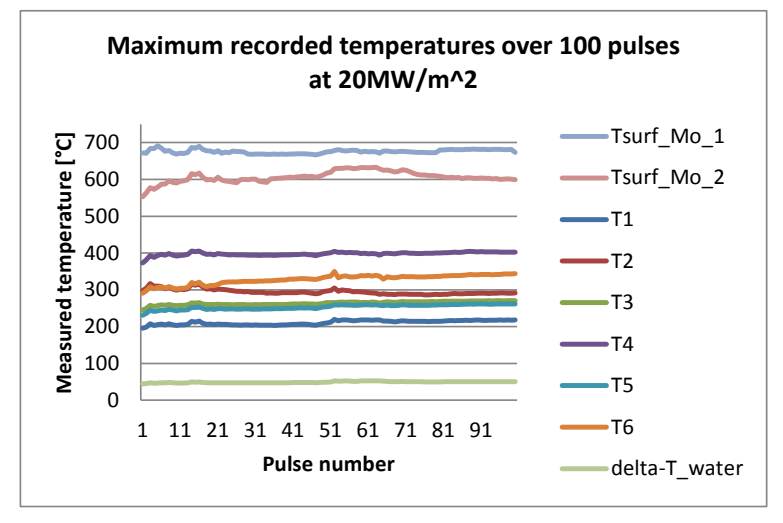

Figure 5: Maximum temperatures measured on the lower prototype over each of the 100 pulses, $10 \mathrm{~s}$ each, at full power $\left(20 \mathrm{MW} / \mathrm{m}^{2}\right)$.

\begin{tabular}{|l|l|l|l|l|l|l|r|r|}
\hline (temperatures in ${ }^{\circ} \mathrm{C}$ ) & T1 & T2 & T3 & T4 & T5 & T6 & Tsurf_Mo & delta-T water \\
\hline $\begin{array}{l}\text { Resulting from CFD+Finite } \\
\text { element analyses }\end{array}$ & 248 & 339 & 279 & 351 & 264 & 301 & 630 & 21.1 \\
\hline $\begin{array}{l}\text { Average of maximum } \\
\text { temperatures recorded in } \\
\text { 100 pulses at full power }\end{array}$ & 211 & 295 & 264 & 398 & 253 & 328 & 642 & 23.0 \\
\hline
\end{tabular}

Table 1: Maximum average temperatures referred to the lower prototype

By comparing, for the various pulses, the trend of the maximum temperatures on the Mo surface shown in Figure 5 , it was not possible to recognize appreciable changes of the peak temperatures. This means that no appreciable damages could be diagnosed on the prototype over 100 pulses, $10 \mathrm{~s}$ each, at $20 \mathrm{MW} / \mathrm{m}^{2}$. A careful visual inspection was carried out on both the prototypes after the test and no damage could be identified. In order to evaluate whether the exposure of the molybdenum surface to the hydrogen beam at $20 \mathrm{MW} / \mathrm{m}^{2}$ caused microscopic damages or modification to the polished molybdenum surface, it was analyzed with Confocal Laser Scanning Microscopy (CLSM) before and after the tests. No appreciable modification of the surface morphology was detected, as shown in Figure 6, at different distances from the GLADIS beam axis (so exposed to different power densities).

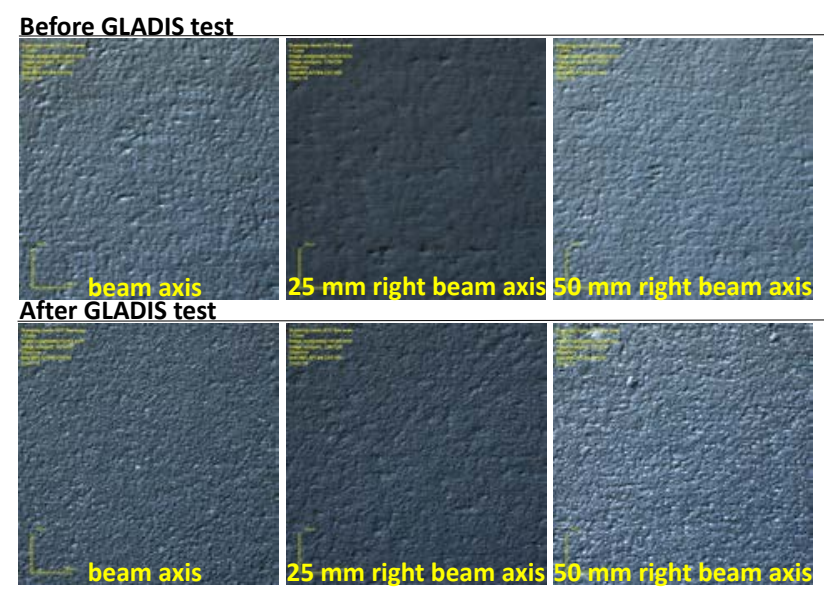

Figure 6: CLMS images of the Mo surface before and after 100 pulses, $10 \mathrm{~s}$ each, at $20 \mathrm{MW} / \mathrm{m}^{2}$, corresponding to a total fluence of $6 * 10^{24} \mathrm{H} / \mathrm{m}^{2}$

\section{CONCLUSIONS}

The tests performed at the GLADIS facility fully confirmed that the prototypes can withstand $>100$ thermal cycles of $20 \mathrm{MW} / \mathrm{m}^{2}$, without showing any kind of damages. This test, together with the other R\&D activities carried out in the past ${ }^{2,6}$, allow to conclude that explosion bonding of 1.0 molybdenum sheet onto a copper substrate forms a reliable joining that can be adopted as suitable technology for manufacturing the MITICA RF source components hit by the highly energetic back accelerated positive ions.

\section{Acknowledgement}

The authors gratefully acknowledge M. Balden, IPP Garching, for the performed confocal laser scanning microscopy. The work leading to this publication has been funded partially by Fusion for Energy. This publication reflects the views only of the author, and Fusion for Energy cannot be held responsible for any use which may be made of the information contained therein. The views and opinions expressed herein do not necessarily reflect those of the ITER Organization.

\footnotetext{
${ }^{1}$ D. Marcuzzi et al., Final Design of the Beam Source for the MITICA Injector, presented at this conference.

2 M. Pavei et al., Molybdenum armour layer on copper plates: Manufacturing technologies and tests of prototypes, Fusion Engineering (SOFE), 2013 IEEE 25th Symposium, DOI 10.1109/SOFE.2013.6635391

${ }^{3}$ H. Greuner et al., J. Nucl. Mater. 367-370 (2007) 1444

${ }^{4}$ L. R. Grisham, et al., Fus. Eng. Des. 87, 1805 (2012)

${ }^{5} \mathrm{~V}$. Toigo, et al., Progress in the realization of the PRIMA Neutral Beam Test Facility, Nucl. Fusion 55 (2015) 083025 (13pp), http://dx.doi.org/10.1088/0029-5515/55/8/083025.

${ }^{6} \mathrm{M}$. Pavei, Studies, analyses, available materials and technologies for plasma facing components - Applications and future improvements for negative Ion sources of neutral beam injectors, $\mathrm{PhD}$ thesis, University of Padova (2012).
} 